Holstein 젖소의 선형심사형질과 등급형질에 대한 유전변이 추정

이득환

한경대학교 동물생명자원학과

\title{
Estimation of Genetic Variations for Linear Type Traits and Composite Traits on Holstein Cows
}

\author{
D. H. Lee \\ Department of Animal Life Resources, Hankyong National University
}

\begin{abstract}
Genetic parameters for linear type and composite traits were estimated by using Bayesian inference via Gibbs sampling with a multiple threshold animal model in Holstein cows. Fifteen linear type traits and 5 composite traits were included to estimate genetic variance and covariance components in the model. In this study, 30,204 records were obtained in the cows from 305 sires. Heritability estimates for linear type traits had the estimates as high as $0.28 \sim 0.64$. Heritability estimates for composite traits were also high, when the traits were assumed to be categorical traits. Final score was more correlated with the composite traits than with the linear type traits.
\end{abstract}

(Key words : Linear type trait, Categorical trait, Threshold model, Holstein, Genetic parameters)

\section{I. 서 론}

10 여년 전부터 낙농선진국의 경우에 젖소의 선형심사에 대한 관심이 크게 집중되었는데 이 는 체형형질(conformation traits)들이 생산수명과 밀접한 관계가 있다고 보고되었으며, (Rogers et al., 1989; Brotherstone and Hill, 1990; Boldman et al., 1992; Short and Lawlor, 1992; Ducrocq and Solkner, 1994) 종축선발을 위하여 선형심사 와 생산수명과의 유전적 관계에 대한 연구가 많이 진행되었다(Weigel et al., 1998; Vollema and Groen, 1998; Schneider et al., 2003). 2005년 현재 미국의 Holstein협회에서는 이러한 선형심 사를 15 개의 1 차 형질(키, 강건성, 체심, 예각 성, 엉덩이기울기, 엉덩이 너비, 옆에서 본 뒷 다리, 발굽기울기, 앞유방 붙임성, 뒷유방 높이,
뒷유방 너비, 정중제인대, 유방깊이, 뒤에서 본 앞유두 배열, 앞유두 크기)로 분류하고 있으며 (Holstein Association USA, 2005) 이들 형질들에 대한 유전평가를 통하여 종축선발에 활용하고 있다. 또한 이들 선형심사점수를 이용한 2차 형질로써 등급에 의하여 조사된 형질로써 일반 외모, 유용특질, 체적, 지제 및 비유기관 등이 있으며 또한 최종점수가 조사되었다. 특히 선 형심사점수를 종합한 3종류의 대표적인 선형종 합지수를 선발에 이용하는데 이는 유방종합지 수, 체형종합지수 및 지제종합지수 등이 그것 이다. 국내의 경우 1980 년대부터 미국의 선형 심사방법을 채택하여 실시하여 왔으며 여기서 조사된 자료는 주로 종모우 선발에 이용하여 왔다. 이러한 선형심사점수의 정의 및 조사방 법은 송 등(2002)에 의하여 보고된 바와 같다.

Corresponding author : D. H. Lee, Department of Animal Life Resources, Hankyong National Univ. Seokjeongdong Anseong-si Gyeonggi-do, Rep. of Korea 456-749

Tel : 031-670-5091, Fax : 031-676-5091, E-mail : dhlee@hnu.hankyong.ac.kr 
본 연구는 국내 Holstein 젖소를 대상으로 조 사된 기능성 형질인 15 개의 선형심사 1 차 형질 과 5 개의 선형심사 2 차 형질들에 있어서 유전 적 변이를 알아보고 형질들간의 유전적 관계를 알아봄으로써 외국 젖소와의 유전적 특이성을 규명하여 젖소 종축선발에 참고자료로 제공하 고자 수행하였다.

\section{ㅍ. 재료 및 방법}

본 연구에 이용된 자료는 2000년부터 2004년 까지 한국종축개량협회 주관으로 Holstein 경산 우를 대상으로 조사된 118,290두의 기록으로부 터 이상치를 제외하였으며 자료의 신뢰도를 높 이기 위하여 농가-심사 시기별(Herd-Appraisal date) 심사두수가 5두 이상인 개체의 기록만을 분석에 포함하였고 또한 종모우당 낭우수가 10 두 이상인 개체의 기록을 분석에 포함하였다. 또한 부 또는 모 중 하나라도 알려진 개체의 기록만을 분석에 포함하였다. 최종 유전분석에 이용된 자료는 혈통정보를 갖고 있는 개체 26,701두로부터 분석대상형질들에 대한 자료가 모두 조사된 30,204기록이었다.

기록분석형질들은 1 차 선형심사형질로써 (1) 전체외모에 대한 선형심사형질로써 십자부의 키 (Stature, ST), 강건성 (Strength, SR), 체심 (Body depth, BD) 및 예각성 (Dairy form, DF) 등이며, (2) 엉덩이부위에 대한 선형심사인 엉 덩이 기울기 (Rump angle, RA) 및 엉덩이 너비 (Thurl width, TW) 등이며, (3) 다리와 발굽부위 에 대한 선형심사형질인 옆에서 본 뒷다리 (Rear leg side view, LS) 및 발굽기울기 (Foot angle, FA) 등이며, (4) 유방부위에 대한 선형심 사형질인 앞유방붙임성 (Fore udder attachment, $\mathrm{FU}$ ), 뒷유방높이 (Rear udder height, $\mathrm{UH}$ ), 뒷유 방너비 (Rear udder width, UW), 정중제인대 (Udder cleft, UC) 및 유방깊이 (Udder depth, UD) 등이었으며 (5) 유두부위의 선형심사형질로써 뒤 에서 본 앞유두배열 (Front teat placement, TP) 및 앞유두크기 (Teat length, TL) 등 이었다. 이 들 선형심사형질들은 0 50점의 범위에서 점수 화되었으며 점수를 부여한 기준은 미국의 표준
점수부여 방식을 채택하였다. 2차 선형심사형 질로써 5 가지의 등급형질이 조사되었는데 이는 일반외모 (General stature composite, GSC), 유용 특질 (Dairy capacity composite, DCC), 체적 (Body size composite, BSC), 지제 (Foot and leg composite, FLC), 및 비유기관 (Udder composite, UDC) 등 이었고 이러한 형질은 excellent, very good, good plus, good, fair 및 poor 등 6단계로 구분하여 지수화 하였다. 또한 이러한 선형심 사형질들을 종합한 최종 점수(Final score, FS) 를 50 100점의 범위에서 점수화 하였다. 위의 2차 선형심사형질들은 1 6점 범위에서 수치변 환 후 분석을 실시하였다.

분석모형은 사전 환경요인들에 대한 분석연 구로부터 수행한 결과(이 등, 투고 중)에 기초 하여 고정효과로써 농가-심사 연월일(HerdAppraisal date), 심사시 연령, 심사시의 착유일 을 월별로 분류한 비유단계 및 착유후 심사개 시시까지 시간간격 등을 분석모형에 고려하였 다. 또한 혈연관계를 고려한 개체의 상가적 유 전효과를 임의효과로 간주하여 분석모형을 설 정하였다. 심사시 연령은 1 세부터 9 세까지 구 분하였는데 9세 이상은 9세로 간주하였다. 비 유단계는 분만후부터 365일까지 월로 계산하여 총 12 월로 구분되었다. 심사시각은 착유개시시 부터 심사개시시까지 시간 간격을 시로 계산하 여 12단계로 구분하였다.

통계분석방법은 다형질 임계개체모형을 각 형질별로 다음과 같이 설정하여 분산분석을 실 시하였다.

$y_{i j k l m n}=\mu+H Y S_{i}+A G E_{j}+S T A G E_{k}+T I M E_{l}+a_{m}+e_{i j k m n}$ 여기서 $\mu$ 는 전체평균, $H_{Y S} i$ 은 $i$ 번째 농가-심 사일효과 $(i=1 \sim 2224), A G E_{j}$ 는 $j$ 번째 개체 연령 효과( $k=1 \sim 9), S T A G E_{k}$ 는 $k$ 번째 비유단계효과 (p=1 12), TIME $l$ 는 $l$ 번째 심사시각 효과 $(q=$ $1 \sim 12), a_{m}$ 은 $m$ 번째 개체의 상가적 유전효과, $e_{i j k l m n}$ 는 잔차효과이며 $y_{i j k l m n}$ 는 각 형질별 관측 치이다.

유전변이를 추정하기 위한 통계적 방법은 15 개의 1 차 선형심사형질들에 대해서는 정규분포 의 연속변량 형질로 간주하였으며 5 개의 2 차 선형심사형질에 대해서는 순서화된 범주형 자 
료로 간주하여 조사된 자료에 대한 잠재변수를 가정하여 아래와 같은 임계모형을 설정하였다.

다변량 범주형 혼합개체모형을 설정하고 Geman과 Geman(1984)이 제시한 Gibbs sampling algorithm을 응용하여 본 분석을 실시하였다. 다변량 통계분석에서 순서화된 범주형 자료로 써 5 개 등급심사형질을 정의하였으며 이를 포 함한 21개 형질에 대한 범주형 모형을 설정하 여 Bayesian inference의 일종인 Gibbs sampling 방법으로 분산성분을 추정하였다. 분석모형에 서 범주형 관측치는 아래와 같이 주어진 범주 구간 내에 관측되지 않는 잠재변수 $(u)$ 가 존재한 다는 가정하에 잠재변수를 생성하였다. 즉, 범 주형 자료의 $i$ 번째 관측치에서 $y_{i}=\lambda$, if $t_{\lambda-1}<$ $u_{i} \leq t_{\lambda}$ 이며 $\lambda$ 은 범주형 자료 $1 \sim \mathrm{C}$ 의 구간 내 에 관측된 관측치이며 각각의 임계값에 대한 벡터 $t=\left(t_{1}, t_{2}, \Lambda, t_{c-1}\right)^{\prime}$ 는 $-\infty=t_{0}<t_{1}<t_{c-1}$ $<t_{c}=\infty$ 의 범위내에 존재한다고 가정하였다. 등급심사형질들에 대한 잠재변수는 연속형 변 량인 15 개 부위의 선형심사형질들을 함께 고려 하여 다변량 혼합개체모형을 설정하고 유전분 석을 실시하였다. 여기서 분석모형은 21개 종 속변수에 대한 벡터를 U로 정의하면

$U=\left(\begin{array}{c}\mathrm{u}_{1} \\ \vdots \\ \mathrm{u}_{21}\end{array}\right) \sim N\left(\left(\begin{array}{c}W \theta_{1} \\ \vdots \\ W \theta_{21}\end{array}\right), R \otimes \mathrm{I}_{n}\right)$ 으로 여기서

$R$ 은 $21 \times 21$ 크기의 잔차 분산-공분산 행렬이고 $\theta$ 는 각 형질의 위치모수이며 $W$ 는 이에 대응 되는 계수행렬이다. $i$ 번째 범주형 형질의 관측 치에 대한 잠재변수는 다음과 같은 분포특성을 갖는 것으로 가정하였다. 즉, $i$ 번째 범주형 형 질의 $j$ 번째 관측치가 $\lambda$ 이라면 이에 대한 잠재 변수는 다음의 확률변수 특성을 갖는다.

$\mathrm{f}\left(\mathrm{u}_{\mathrm{ij}} \mid \mathrm{y}_{\mathrm{ij}}=\ell, \mathrm{u}_{-\mathrm{ij}}, \theta, \mathrm{R}, \mathrm{t}\right)=\frac{\phi\left(\frac{\mathrm{u}_{\mathrm{ij}}-\xi_{\mathrm{ij}}}{\sigma_{\mathrm{i}}}\right)}{\Phi\left(\frac{\mathrm{t}_{\mathrm{i} \ell}-\xi_{\mathrm{ij}}}{\sigma_{\mathrm{i} \cdot}}\right)-\Phi\left(\frac{\mathrm{t}_{\mathrm{i} \ell-1}-\xi_{\mathrm{ij}}}{\sigma_{\mathrm{i} .}}\right)} 1\left(\mathrm{u}_{\mathrm{ij}} \in\left[\mathrm{t}_{\mathrm{i} \ell-1, \mathrm{t}} \mathrm{t}_{\mathrm{i} \ell}\right)\right)$

따라서 주어진 임계값, 기타형질에 대한 관 측치, 지역모수, 잔차분산 및 관측치 $\lambda$ 에서 잠 재변수에 대한 조건확률분포는 다음과 같이 표 현할 수 있다.

$$
\mathrm{u}_{\mathrm{ij}} \mid \mathrm{y}_{\mathrm{ij}}=\ell, \mathrm{u}_{-\mathrm{ij}}, \theta, \mathrm{R}, \mathrm{t} \sim \mathrm{TN}_{\mathrm{t}_{\mathrm{i} \ell-1}, \mathrm{t}_{\mathrm{i} \ell}}\left(\xi_{\mathrm{ij}}, \sigma_{\mathrm{i}}^{2}\right)
$$

여기서 $u_{-i j}$ 는 $u_{i j}$ 를 제외한 기타 잠재변수 및 연속변량을 갖는 형질들에 대한 관측치를 의미 하고, $\phi(\cdot)$ 와 $\Phi(\cdot)$ 는 표준정규분포에서 확률밀도 함수(probability density function)와 누적밀도함수 (cumulated density function)를 의미하며, $\mathrm{TN}$ 는 절 단형 정규분포함수를 의미한다. 또한 절단형 정규 분포함수에서 평균 $\zeta_{i j}=w_{i j}^{\prime} \theta_{i}+R_{i(-i)} R_{(-i)(-i)}^{-1} e_{-i j}$ 로, 분산 $\sigma_{i}^{2}=r_{i i}-R_{i(-i)} R_{(-i)(-i)}^{-1} R_{(-i) i}$ 으로 계산 한다. 여기서 잔차분산 $R=\left[\begin{array}{ll}r_{i i} & R_{i(-i)} \\ R_{(-i) i} & R_{(-i)(-i)}\end{array}\right]$ 이다.

임의로 생성된 잠재변수에 대한 변이의 크기 와 중심치를 결정해야 하는 문제(identifiability) 가 발생한다. 이를 위하여 Sorensen 등(1995)은 임계값의 하나를 “ 0 ”으로 제한하고 잔차분산을 “1”로 제한하는 방법을 사용할 수 있다고 하 였는데 본 연구에서는 2 개의 인접한 임계값을 “0”과 “ 1 ”로 제한하여 잠재변수를 생성하였다.

Gibbs sampling에 의한 임계값의 생성은 Sorensen 등(1995)이 제시한 다음과 같은 방법으로 생성 하였다.

$\mathrm{t}_{\mathrm{i} \lambda}^{\mathrm{n}} \mid \theta, \mathrm{R}, \mathrm{G}, \mathrm{t}_{-\mathrm{i} \lambda}, \mathrm{U}, \mathrm{Y}^{0} \sim \mathrm{UN}\left(\max \left(\max _{j}\left(u_{i j}^{*} \mid y_{i j}=\lambda\right)\right.\right.$, $\left.\min \left(\min _{j}\left(u_{\mathrm{ij}}^{*} \mid \mathrm{y}_{\mathrm{ij}}=\lambda+1\right), \mathrm{t}_{\mathrm{i} \lambda+1}^{\mathrm{n}-1}\right)\right)$

여기서 UN은 uniform distribution을 의미한다. 지역모수(location parameter)와 분산모수(dispersion parameter)에 대한 사후분포특성을 규명하기 위 해서는 이들 모수에 대한 사전분포특성을 정의 해야 한다. 본 연구에서는 각 모수에 대한 사 전분포를 다음과 같이 가정하였다.

(a) $f(\beta) \propto$ const

(b) $f(a \mid G) \sim N(0, G \otimes A)$

여기서 $G$ 는 21 가지 형질들에 대한 $21 \times 21$ 유전 분산-공분산 행렬이고 $A$ 는 개체들간의 혈연계 수 행렬이다. 유전 분산-공분산 성분과 환경 분산-공분산 성분에 대한 사전정보를 모르기 때문에 Jeffrey의 noninformative priors (Gelman et al., 1995)를 적용하여 아래와 같이 가정하였다.

(c) $f(R) \propto|R|^{-k / 2}$

(d) $f(G) \propto|G|^{-k}$

각 모수에 대한 사전정보에 따라 사후조건확률 분포의 지역모수는 van Tassell 등(1998)이 제시한 방법에 따라 다변량 정규분포 함수에서 Gibbs sampler를 적용하였으며 분산-공분산 성분은 
inverted Wishart 분포함수에서 생성하였다. 각 모수에 대한 Gibbs sampler를 적용하기 위한 모 수의 초기치로써 임계값의 초기치는 0 부터 1 씩 증가하여 부여하였으며, 지역모수의 초기치는 각 sub-class에 대한 단순평균을 적용하였고, 분 산-공분산 성분은 모의실험자료를 생성하기 위하여 사용된 모수를 적용하였다.

유전 및 환경에 있어서 각 형질간 상호작용 이 있는 것을 가정하여 분석을 실시하였으며 100,000 회의 Gibbs sampler를 실시하여 초기 10,000회는 burn-in기간으로 간주하였으며, 이후 90,000 회의 각 모수에 대한 사후분포특성을 알 아보았다. 또한 각 분산-공분산 성분 모수에 대한 사후분포 Gibbs sample을 이용하여 유전 력 및 유전상관, 표현형상관을 계산하여 각각 의 유전모수에 대한 사후분포 특성을 알아보았 다.

\section{III. 결과 및 고찰}

\section{1. 일반능력}

본 연구에 이용된 자료는 325두의 종모우로 부터 출생한 30,204두의 낭우에서 조사된 선형 심사자료를 이용하였으며(Table 1) 총 축군수는 2,224 농가에서 조사되었다. 평균 착유개시후 6 시간 후에 선형심사를 실시하였으며 평균 연령 은 2.9세에 실시되었다.

또한 2차 선형심사형질인 GSC, DCC, BSC, FLC 및 UDC 등은 1 6점 분포로 비선형 범주 형 자료로 조사되었으며 이들 조사자료의 분포 는 Figure 1 에 제시된 바와 같이 중간점수를 갖
는 개체가 가장 많은 것으로 조사되었다. Figure 1에서 excellent 점수를 받은 개체는 극소수여서 Figure 1 에서 거의 나타나지 않았으며, very $\operatorname{good}$ 을 받은 개체 역시 소수이었고, 조사된 자 료의 점수 분포가 정규성을 크게 위반하고 있 었기 때문에 선형 함수식에 의한 분석은 적합 하지 않았으며 이에 최적한 범주형 혼합개체모 형을 사용하였다. 다변량 범주형 혼합개체모형 에 의하여 추정된 2차 선형심사형질들에 대한 임계값에 대한 Gibbs sampling을 plot하여 다음 의 Figure 2에 제시하였다.

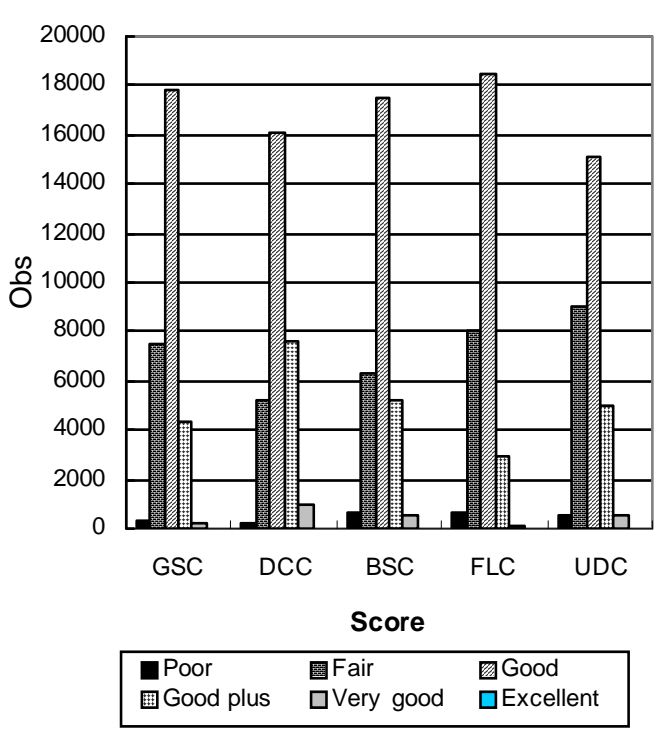

GSC : General stature composite, DCC : Dairy capacity composite, BSC : Body size composite, FLC: Foot and leg composite, UDC: Udder composite

Fig. 1. Plots of type scoring traits in Holstein cows.

Table 1. Information of data structure for linear type traits and type scoring traits in Holstein cows

\begin{tabular}{lcccrr}
\hline & $\mathrm{N}$ & Mean & SD & Min. & Max. \\
\hline \hline No. records/sire & 325 & 92.9 & 173.8 & 11 & 1212 \\
No. records/HYS & 2224 & 13.6 & 9.2 & 1 & 163 \\
Age(yrs) & 30204 & 2.91 & 1.21 & 1 & 9 \\
Lactation stage & 30204 & 5.59 & 3.09 & 1 & 12 \\
Time after milking(hrs) & 30204 & 6.07 & 2.52 & 1 & 12 \\
\hline
\end{tabular}

\footnotetext{
1) Herd-Year-Season.
} 
Figure 2에 제시된 바와 같이 일반외모에 대 한 첫번째 및 2 번째 임계값은 1과 2로 제한을 가하고 나머지 3, 4, 및 5차 임계값의 Gibbs Sampling에 대한 plot은 안정적으로 sampling되는 것을 알 수 있었다. 또한 기타의 형질들에 대 한 임계값들도 유사한 결과를 얻을 수 있었다.

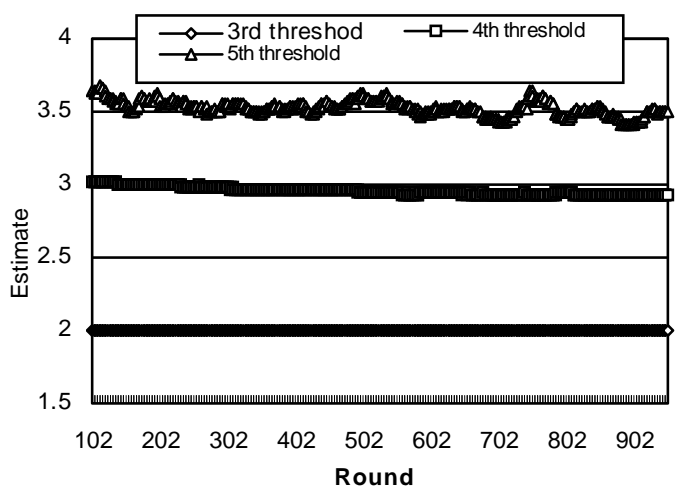

Fig. 2. Plot of Gibbs sampling for thresholds on general stature composite index with threshold animal model in Holstein cows.

\section{2. 유전력}

또한 1 차 선형심사형질들에 대한 다변량 범 주형 혼합개체모형에서 추정된 유전력은 다음 의 Table 2과 같다. Table 2에 제시된 바와 같 이 1 차 선형심사형질에 대한 유전력은 대부분 높게 추정되었는데 특히 외모에 대한 선형심사 형질은 ST, SR, BD 및 $\mathrm{DF}$ 에서 $0.64,0.42,0.49$ 및 0.33 으로 추정되었고, 엉덩이부위에 대한 선
형심사인 RA 및 TW는 각각 0.66 및 0.47 으로 추정되었으며, 다리와 발굽부위에 대한 선형심 사형질인 LS 및 FA에서 0.32 및 0.29 으로 추정 되었다. 유방부위에 대한 선형심사형질인 $\mathrm{FU}$ 는 $0.46, \mathrm{UH}$ 는 $0.45, \mathrm{UW}$ 는 0.35 , UC는 0.28 및 UD 는 0.49 으로 추정되었다. 유두부위의 선형심사 형질로써 $\mathrm{TP}$ 및 $\mathrm{TL}$ 의 유전력은 각각 0.53 및 0.64 으로 추정되었다. 이러한 추정치는 각 선형 심사형질에 대한 개량 가능성이 높을 것으로 사료되었으며 상대적으로 미국에서 발표한 각 각의 형질에 대한 유전력보다 상당히 높게 추 정되어 개체간의 변이가 그만큼 큰 것을 알 수 있었다.

2차 선형심사형질로써 5가지의 등급형질에 대한 유전력은 GSC에서 0.46, DCC는 0.37, $\mathrm{BSC}$ 는 0.50 , FLC의 경우 0.32, 및 UDC는 0.47 로 높게 추정되었다(Table 3). 만일 이러한 형 질들을 선형으로 간주하여 추정하면 이보다 다 소 낮게 추정될 것으로 사료된다.

Table 3. Fully conditional posterior means and Monte-Carlo standard deviations for heritabilities of linear composite traits in Holstein cows

\begin{tabular}{lcc}
\hline Trait(abbr.) & Mean & SD \\
\hline \hline General stature composite index(GSC) & 0.46 & 0.02 \\
Dairy capacity composite index(DCC) & 0.37 & 0.02 \\
Body size composite index(BSC) & 0.50 & 0.01 \\
Foot and leg composite index(FLC) & 0.32 & 0.01 \\
Udder composite index(UDC) & 0.47 & 0.01 \\
\hline
\end{tabular}

Table 2. Fully conditional posterior means and Monte-Carlo standard deviations for heritabilities of linear type traits and final score in Holstein cows

\begin{tabular}{lcc|lcc}
\hline Trait(abbr.) & Mean & SD & Trait(abbr.) & Mean & SD \\
\hline \hline Stature(ST) & 0.64 & 0.01 & Fore udder attachment(FU) & 0.46 & 0.02 \\
Strength(SR) & 0.42 & 0.01 & Rear udder height(UH) & 0.45 & 0.02 \\
Body depth(BD) & 0.49 & 0.02 & Rear udder width(UW) & 0.35 & 0.02 \\
Dairy form(DF) & 0.33 & 0.01 & Udder cleft(UC) & 0.28 & 0.02 \\
Rump angle(RA) & 0.66 & 0.01 & Udder depth(UD) & 0.49 & 0.01 \\
Thurl Width(TW) & 0.47 & 0.02 & Front teat placement(TP) & 0.53 & 0.01 \\
Lear leg side view(LS) & 0.32 & 0.02 & Teat length(TL) & 0.64 & 0.01 \\
Foot angle(FA) & 0.29 & 0.01 & Final score(FS) & 0.54 & 0.01 \\
\hline
\end{tabular}


3. 유전상관

1차 선형심사형질들에 대한 유전 및 표현형 상관 추정치는 Table 4와 같다. Table 4에 제시 된 바와 같이 전체외모에 대한 형질들 간의 유 전상관을 제외하고는 나머지 형질들 간에 유전 상관 추정치는 다소 낮은 것으로 추정되었는데 $\mathrm{FS}$ 와 UW와는 0.79 의 강한 유전상관이 있는 것 으로 추정되었다. 반면에 $\mathrm{LS}$ 와 $\mathrm{FS}$ 와는 -0.27 로
부의 유전상관이 있는 것으로 추정되었다. 또 한 $\mathrm{DF}$ 과 $\mathrm{FS}$ 와는 0.72 의 강한 정의 유전상관이 있는 것으로 추정되었다.

2차 선형심사형질 간에는 상대적으로 강한 정의 상관관계가 있는 것으로 추정되었다. 특 히 $\mathrm{GSC}$ 와 $\mathrm{BSC}$ 간에는 0.72 의 강한 유전상관이 있는 반면에 FLC와 DCC간에는 0.28 의 약한 정 의 유전상관이 있는 것으로 추정되었다(Table 5). 1 차 선형심사형질과 2 차 선형심사형질 사이

Table 4. Fully conditional posterior means for heritabilities (diagonal), genetic correlation (upper diagonal) and phenotypic correlation (below diagonal) of linear type traits and final score in Holstein cows

\begin{tabular}{lcccccccccccccccc}
\hline & ST & SR & BD & DF & RA & TW & LS & FA & FU & UH & UW & UC & UD & TP & TL & FS \\
\hline \hline ST & $\mathbf{0 . 6 4}$ & 0.34 & 0.45 & 0.29 & 0.18 & 0.46 & -0.11 & 0.28 & 0.05 & 0.08 & 0.21 & 0.11 & 0.15 & 0.00 & 0.13 & 0.39 \\
SR & 0.30 & $\mathbf{0 . 4 2}$ & 0.77 & 0.24 & -0.14 & 0.49 & -0.16 & 0.30 & 0.22 & 0.04 & 0.44 & 0.10 & -0.24 & 0.02 & 0.13 & 0.58 \\
BD & 0.37 & 0.61 & $\mathbf{0 . 4 9}$ & 0.50 & -0.09 & 0.54 & -0.08 & 0.23 & 0.22 & 0.09 & 0.44 & 0.18 & -0.24 & 0.09 & 0.10 & 0.63 \\
DF & 0.18 & 0.17 & 0.37 & $\mathbf{0 . 3 3}$ & -0.04 & 0.28 & 0.10 & 0.18 & 0.29 & 0.48 & 0.48 & 0.40 & 0.03 & 0.08 & 0.01 & 0.72 \\
RA & 0.16 & -0.06 & -0.01 & 0.00 & $\mathbf{0 . 6 6}$ & -0.04 & 0.10 & -0.14 & -0.16 & 0.02 & -0.10 & -0.16 & -0.05 & -0.05 & 0.00 & -0.15 \\
TW & 0.34 & 0.37 & 0.41 & 0.22 & -0.01 & $\mathbf{0 . 4 7}$ & 0.04 & 0.12 & 0.09 & 0.07 & 0.39 & 0.12 & -0.12 & 0.04 & 0.08 & 0.43 \\
LS & -0.06 & -0.05 & 0.00 & 0.11 & 0.08 & 0.01 & $\mathbf{0 . 3 2}$ & -0.60 & -0.14 & -0.01 & -0.18 & 0.06 & -0.05 & 0.03 & -0.09 & -0.27 \\
FA & 0.14 & 0.11 & 0.09 & 0.04 & -0.08 & 0.08 & -0.32 & $\mathbf{0 . 2 9}$ & 0.23 & 0.05 & 0.22 & 0.14 & 0.07 & -0.02 & 0.04 & 0.46 \\
FU & 0.05 & 0.15 & 0.15 & 0.17 & -0.10 & 0.08 & -0.07 & 0.11 & $\mathbf{0 . 4 6}$ & 0.46 & 0.41 & -0.06 & 0.51 & 0.19 & -0.02 & 0.56 \\
UH & 0.04 & 0.05 & 0.07 & 0.26 & 0.02 & 0.08 & -0.03 & 0.07 & 0.30 & $\mathbf{0 . 4 5}$ & 0.68 & 0.33 & 0.31 & 0.05 & 0.01 & 0.60 \\
UW & 0.16 & 0.28 & 0.31 & 0.31 & -0.04 & 0.31 & -0.06 & 0.11 & 0.27 & 0.45 & $\mathbf{0 . 3 5}$ & 0.24 & 0.00 & 0.07 & 0.07 & 0.79 \\
UC & 0.04 & 0.02 & 0.06 & 0.17 & -0.06 & 0.06 & 0.01 & 0.06 & 0.12 & 0.21 & 0.14 & $\mathbf{0 . 2 8}$ & 0.27 & 0.29 & 0.06 & 0.42 \\
UD & 0.06 & -0.17 & -0.22 & -0.03 & -0.03 & -0.11 & -0.06 & 0.09 & 0.29 & 0.18 & -0.11 & 0.18 & $\mathbf{0 . 4 9}$ & 0.17 & -0.07 & 0.17 \\
TP & -0.01 & 0.04 & 0.06 & 0.06 & -0.04 & 0.03 & 0.02 & 0.02 & 0.17 & 0.05 & 0.06 & 0.21 & 0.14 & $\mathbf{0 . 5 3}$ & -0.25 & 0.17 \\
TL & 0.12 & 0.11 & 0.11 & 0.04 & 0.00 & 0.11 & -0.02 & 0.03 & 0.02 & 0.03 & 0.10 & 0.03 & -0.07 & -0.12 & $\mathbf{0 . 6 4}$ & 0.03 \\
FS & 0.31 & 0.43 & 0.51 & 0.55 & -0.09 & 0.37 & -0.13 & 0.28 & 0.45 & 0.48 & 0.62 & 0.26 & 0.07 & 0.16 & 0.09 & $\mathbf{0 . 5 4}$ \\
\hline
\end{tabular}

ST : Stature, SR : Strength, BD : Body depth, DF : Dairy form, RA : Rump angle, TW : Thurl width, LS : Rear leg side view, FA : Foot angle, FU: Fore udder attachment, UH: Rear udder height, UW: Rear udder width, UC : Udder cleft, UD : Udder depth, TP : Front teat placement, TL : Teat length, FS : Final score.

Table 5. Fully conditional posterior means for heritabilities (diagonal), genetic correlation (upper diagonal) and phenotypic correlation (below diagonal) of linear composite traits in Holstein cows

\begin{tabular}{llllll}
\hline & GSC & DCC & BSC & FLC & UDC \\
\hline \hline GSC & $\mathbf{0 . 4 6}$ & 0.61 & 0.72 & 0.58 & 0.51 \\
DCC & 0.41 & $\mathbf{0 . 3 7}$ & 0.47 & 0.28 & 0.56 \\
BSC & 0.51 & 0.32 & $\mathbf{0 . 5 0}$ & 0.36 & 0.35 \\
FLC & 0.34 & 0.13 & 0.20 & $\mathbf{0 . 3 2}$ & 0.42 \\
UDC & 0.35 & 0.37 & 0.25 & 0.26 & $\mathbf{0 . 4 7}$ \\
\hline
\end{tabular}

GSC : General stature composite, DCC : Dairy capacity composite, BSC : Body size composite, FLC : Foot and leg composite, UDC : Udder composite. 
의 유전상관은 Table 6에 제시하였는데 RA는 2 차 선형심사형질들과 부의 상관관계가 있는 것 으로 추정되었다. 반면에 $\mathrm{FS}$ 의 경우 2차 선형 심사형질들과 강한 정의 유전상관이 있는 것으 로 추정되었는데 GSC와 $0.81, \mathrm{DCC}$ 와 0.73 , $\mathrm{BSC}$ 와 $0.67, \mathrm{FLC}$ 와 0.63 그리고 $\mathrm{UDC}$ 와는 0.86 으로 높게 추정되었다.

이러한 결과로 살펴볼 때, 선형심사형질들에 대한 유전적 변이는 상당히 큰 것으로 사료되 며 특히 FS는 2차 선형심사와 높은 유전상관을 보이고 있으므로 2차 선형심사를 통한 선발을

Table 6. Fully conditional posterior means for genetic correlations between linear type traits and linear composite traits in Holstein cows

\begin{tabular}{lrrrrr}
\hline & GSC & DCC & BSC & FLC & UDC \\
\hline ST & 0.59 & 0.30 & 0.43 & 0.31 & 0.19 \\
SR & 0.62 & 0.26 & 0.87 & 0.43 & 0.30 \\
BD & 0.70 & 0.51 & 0.98 & 0.30 & 0.32 \\
DF & 0.59 & 0.99 & 0.46 & 0.25 & 0.56 \\
RA & -0.14 & -0.03 & -0.11 & -0.15 & -0.13 \\
TW & 0.58 & 0.30 & 0.55 & 0.12 & 0.30 \\
LS & -0.29 & 0.09 & -0.12 & -0.65 & -0.17 \\
FA & 0.44 & 0.19 & 0.26 & 0.92 & 0.26 \\
FU & 0.31 & 0.25 & 0.26 & 0.32 & 0.69 \\
UH & 0.26 & 0.50 & 0.10 & 0.18 & 0.80 \\
UW & 0.50 & 0.51 & 0.48 & 0.36 & 0.84 \\
UC & 0.29 & 0.42 & 0.17 & 0.23 & 0.41 \\
UD & 0.07 & 0.01 & -0.23 & 0.15 & 0.35 \\
TP & 0.09 & 0.11 & 0.07 & 0.05 & 0.16 \\
TL & 0.05 & -0.01 & 0.11 & 0.04 & -0.02 \\
FS & 0.81 & 0.73 & 0.67 & 0.63 & 0.86 \\
\hline ST
\end{tabular}

ST : Stature, SR : Strength, BD : Body depth, DF : Dairy form, RA : Rump angle, TW : Thurl width, LS : Rear leg side view, FA : Foot angle, FU : Fore udder attachment, UH : Rear udder height, UW : Rear udder width, UC : Udder cleft, UD : Udder depth, TP : Front teat placement, TL : Teat length, GSC : General stature composite, DCC : Dairy capacity composite, BSC : Body size composite, FLC : Foot and leg composite, UDC : Udder composite, FS : Final score.
실시하면 강건성 및 생산수명을 상당히 높일 수 있을 것으로 사료되었다.

$$
\text { IV. 사 사 }
$$

이 논문은 정부(교육인적자원부)의 재원으로 한국학술진흥재단의 지원을 받아 수행된 연구 임(R05-2003-000-11466). 본 연구를 원활히 수행 할 수 있도록 많은 자료협조를 하여주신 한국 종축개량협회에 감사드립니다.

\section{$\mathrm{V}$. 인 용 문 헌}

1. Boldman, K. G., Freeman, A. E., Harris, B. L. and Kuck, A. L. 1992. Prediction if sire transmitting abilities for herd life from transmitting abilities for linear type traits. J. Dairy Sci. 75:552-563.

2. Brotherstone, S. and Hill, W. G. 1990. Dairy herd life in relation to type traits and production. Proc. $4^{\text {th }}$ World Congr. Genet. Appl. Livest. Prod., Edinburgh, Scotland 14:209-212.

3. Ducrocq, V. P. and Solkner, J. 1994. "The survival kit”, a FORTRAN package for the analysis of survival data. Proc. $5^{\text {th }}$ World Congr. Genet. Appl. Livest. Prod., Guelph, ON, Canada 22:51-52.

4. Gelman, A., Carlin, J. B., Stern, H. S. and Rubin, D. B. 1995. Bayesian data analysis. Chapman \& Hall.

5. Geman, S. and Geman, D. 1984. Stochastic relaxation, Gibbs distributions and the Bayesian restoration of images. IEEE Trans. Pattern Anal. Mach. Intel. 6: 721-741.

6. Holstein Association USA. 2005. http://www.holsteinusa. com/ Dec. 12, 2005 accessed.

7. Rogers, G. W., McDaniel, B. T., Dentine, M. R. and Funk, D. A. 1989. Genetic correlations between survival and linear type traits measured in first lactation. J. Dairy Sci. 72:523-527.

8. Schneider, M. P., Durr, J. W., Cue, R. I. and Monardes, H. G. 2003. Impact of type traits on functional herd life of Quebec Holsteins assessed by survival analysis. J. Dairy Sci. 86:4083-3089.

9. Short, T. H. and Lawlor, T. L. 1992. Genetic 
parameters of conformation traits, milk yield, and herd life in Holsteins. J. Dairy Sci. 75:1987-1998.

10. Sorensen, D. A., Andersen, S., Gianola, D. and Korsgaard, I. 1995. Bayesian inference in threshold models using Gibbs sampling. Genet. Sel. Evol. 27:229-249.

11. VanTassell, C. P., VanVleck, L. D. and Gregory, K. E. 1998. Bayesian analysis of twinning and ovulation rates using a multiple-trait threshold model and Gibbs sampling. J. Anim. Aci. 76:2048-2061.

12. Vollema, A. R. and Groen, A. F. 1998. Conformation traits in survival analysis of longevity in dairy cattle. Proc. $6^{\text {th }}$ World Congr. Genet. Appl. Livest. Prod., Armidale, NSW, Australia 23:371374.
13. Weigel, K. A., Lawlor, T. L., Vanraden, P. M. and Wiggans, G. R. 1998. Use of linear type and production data to supplement early predicted transmitting abilities for production life. J. Dairy Sci. 81:2040-2044.

14. 송치은, 상병찬, 도창희. 2002. 국내 홀스타인젖 소의 선형심사에 대한 보정계수 개발. 한국동물 자원과학회지 44:1-12.

15. 이득환, 김은길. 2005. Holstein 젖소의 선형심사 형질과 등급형질에 대한 일반능력 분석. 한국동 물자원과학회지. 투고 중

(접수일자 : 2005. 10. 26. / 채택일자 : 2006. 2. 21.) 